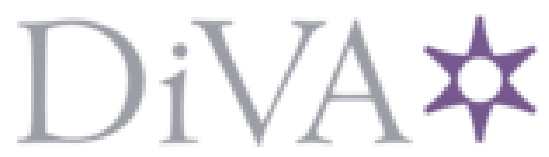

http://www.diva-portal.org

\title{
Postprint
}

This is the accepted version of a paper published in Engineering structures. This paper has been peerreviewed but does not include the final publisher proof-corrections or journal pagination.

Citation for the original published paper (version of record):

Dorn, M., de Borst, K., Eberhardsteiner, J. (2013)

Experiments on dowel-type timber connections.

Engineering structures, 47: 67-80

http://dx.doi.org/10.1016/j.engstruct.2012.09.010

Access to the published version may require subscription.

N.B. When citing this work, cite the original published paper.

Permanent link to this version:

http://urn.kb.se/resolve?urn=urn:nbn:se:lnu:diva-2486 1 


\section{Experiments on dowel-type timber connections}

Dorn, Michael $^{\mathrm{ac}}$, de Borst, Karin ${ }^{\mathrm{b}}$, Eberhardsteiner, Josef ${ }^{\mathrm{c}}$

a Linnaeus University, School of Engineering, Lückligs Plats 1, 35195 Växjö, Sweden. michael.dorn@Inu.se

${ }^{\mathrm{b}}$ University of Glasgow, School of Engineering, Rankine Building, Glasgow G12 8QQ, Scotland, United Kingdom

'Vienna University of Technology, Institute for Mechanics of Materials and Structures, Karlsplatz 13/e202, 1040 Vienna, Austria

Engineering Structures, 47:67-80, 2013.

http://dx.doi.org/10.1016/j.engstruct.2012.09.010

Available under the conditions of Green open access as the post-print version of the accepted article. See also https://www.elsevier.com/journals/engineering-structures/0141-0296

http://www.sherpa.ac.uk/romeo/search.php?issn=0141-0296 


\title{
Experiments on dowel-type timber connections
}

\author{
Michael Dorn ${ }^{\mathrm{a}, \mathrm{c}}$, Karin de Borst ${ }^{\mathrm{b}}$, Josef Eberhardsteiner ${ }^{\mathrm{c}}$ \\ ${ }^{a}$ Linnaeus University, School of Engineering \\ 35195 Växjö, Sweden \\ ${ }^{b}$ University of Glasgow, School of Engineering \\ Rankine Building, Glasgow G12 8QQ, Scotland \\ ${ }^{c}$ Vienna University of Technology, Institute for Mechanics of Materials and Structures \\ Karlsplatz 13/e202, 1040 Vienna, Austria
}

\begin{abstract}
Dowel-type connections are commonly used in timber engineering for a large range of structural applications. The current generation of design rules is largely based on empiricism and testing and lacks in many parts a stringent mechanical foundation. This often blocks an optimized use of the connections, which is essential for the design of economically efficient structures. Moreover, it severely limits the applicability of the design rule, such as restrictions regarding splitting behavior or maximum ductility (e.g. maximum allowable deformations) are missing. Therefore, the demands due to a large and quickly evolving variety of structural designs in timber engineering are not reflected.

The aim of this work is to study the load-carrying behavior of the connection in detail, including all loading stages, from the initial contact between dowel and wood up to the ultimate load and failure. Distinct features during first loading as well as during unloading and reloading cycles are identified and discussed. The knowledge of the detailed load-carrying behavior is essential to understanding the effects of individual parameters varied in relation to the material and the connections design. The suitability of the current design rules laid down in Eurocode 5 (EC5) is assessed and deficiencies revealed.

Tests on 64 steel-to-timber dowel-type connections loaded parallel to the fiber direction were performed. The connections were single-dowel connec-
\end{abstract}

\footnotetext{
Email addresses: michael.dorn@lnu.se (Michael Dorn), karin.deborst@glasgow.ac.uk (Karin de Borst), josef.eberhardsteiner@tuwien.ac.at (Josef Eberhardsteiner)
} 
tions with dowels of twelve millimeter diameter. The test specimens varied in wood density and geometric properties. Additionally, the effects of dowel roughness and lateral reinforcement were assessed. The experiments confirmed that connections of higher density show significantly higher ultimate loads and clearly evidenced that they are more prone to brittle failure than connections using light wood. The latter usually exhibit a ductile behavior with an extensive yield plateau until final failure occurs. With increased dowel roughness, both, ultimate load and ductility are increased.

The test results are compared with corresponding design values given by EC5 for the strength and the stiffness of the respective single-dowel connections. For connections of intermediate slenderness, EC5 provided conservative design values for strength. Nevertheless, in some of the experiments the design values overestimated the actual strengths considerably in connections of low as well as high slenderness. As for the stiffness, a differentiation according to the connection width is missing, which gives useful results only for intermediate widths.

Furthermore, the test results constitute valuable reference data for validating numerical simulation tools, which are currently a broad field of intensive interest.

Keywords:

dowel-type timber connections, Johansen theory, uniaxial tension tests on connections, ductile and brittle failure modes, influence of density, connection design and dowel roughness, comparison with design rules in Eurocode 5

\section{Introduction}

Dowel connections are common types of connections in timber engineering. They are simple to produce and can be used for small as well as for large forces. Figure 1 shows a typical steel-to-timber connection tested in the series of the experiments with a single dowel.

\subsection{Background}

The mechanical behavior of these types of connections was first described scientifically by Johansen in 1949 [1]. Johansen's theory distinguishes three different failure modes, but does not account for potential brittle failure modes. With changes and adaptions, this theory is the basis for the so-called 

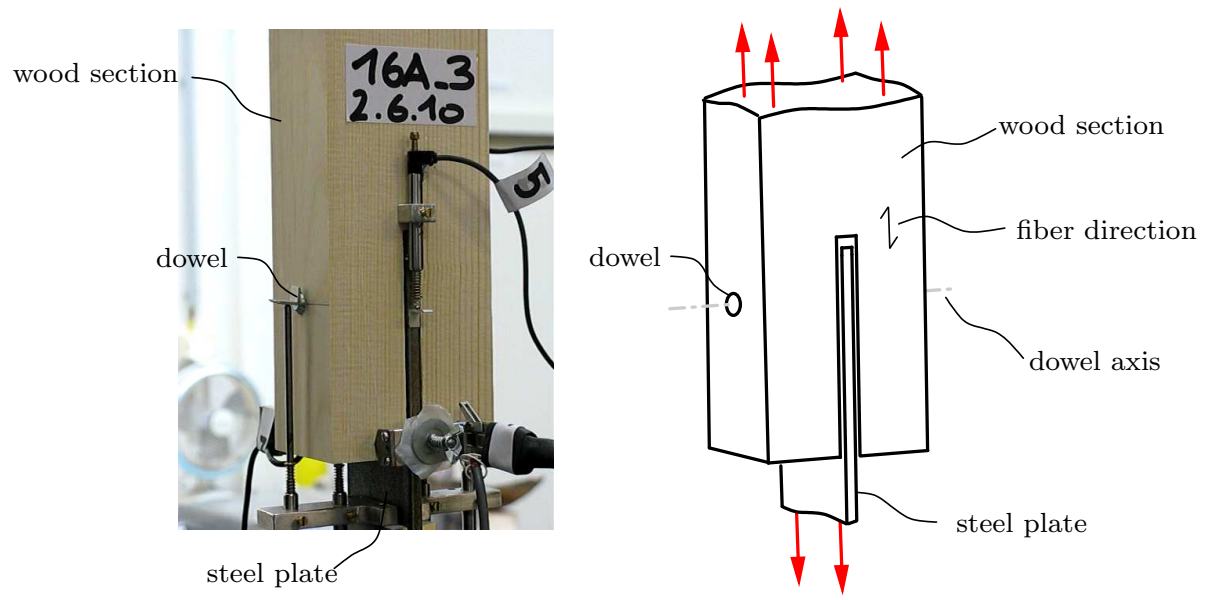

Figure 1: Typical dowel-type timber connection with a single dowel; photo of a specimen during conduction of the experiment (left), sketch (right)

European Yield Model which is used in the current generation of design codes (Eurocode 1995 - EC5) for timber structures [2]. However, this model lacks a stringent mechanical basis. When determining the stiffness of the connection, its thickness is not considered. Slim as well as thick connections have equal stiffnesses which is not realistic. Moreover, the connection design does not take compatibility of displacements into account, and there are no restrictions on maximum displacements.

The design of multi-dowel connections is based on the behavior of a single dowel. The ultimate load is upscaled by an effective number of acting dowels, depending on the distances between the dowels. Also the overall stiffness of the connection is derived by multiplying the stiffness of a single dowel by the number of active dowels.

\subsection{State of the Art}

Many questions remain open, resulting in high research activity in this field. Particularly multi-dowel connections are studied, where a large variety of connection lay-outs is possible [3,4]. Thereby, the main challenge is to resolve the statically indeterminant distribution of forces to the individual dowels and to thereon determine the effective number of dowels to be taken into account in the design, depending on e.g. dowel spacing and edge distance. More sophisticated studies deal for example with the pretensioning of the connection by bolts [5], with the behavior of the connection under 
fire loads [6], or with the influence of moisture changes on the connective behavior [7] and embedment [8]. Some studies focus on wood splitting in connections loaded parallel as well as perpendicular to the grain direction $[9,10]$.

Modeling of connections is currently receiving particular interest, applying numerical simulation techniques such as the Finite-Element method. Most of the numerical models are developed for plane-stress conditions only [11], [12], therefore neglecting three-dimensional effects. Other simulation approaches use solid elements for modeling the wooden parts, but investigate it to thin members only, for which again the bending of the dowel can be neglected $[13,14]$. Only a limited number of numerical models is applied to wide connections, in which dowel bending is crucial $[15,16]$. The influence of friction on the mechanical behavior of the connection has been studied in experiments as well as in simulations [17]. Typically, static friction coefficients between 0.1 to 0.7 are assumed in the simulations, which is a parameter heavily influencing load capacity and the occurrence of brittle failure, but not thoroughly verified experimentally. For the purpose of checking the suitability of modeling approaches and results of simulations there is need for reliable experimental data.

\subsection{Aim}

This paper deals with the analysis and description of the load-carrying characteristics of dowel-type steel-to-timber connections. The focus is placed on experimental investigations of single-dowel connections which has the benefit that there are no effects of statically indeterminant load distribution.

The experiments aim at an improved understanding of the load-carrying behavior in detail at every load stage, from the initial formation of contact between wood and the dowel, to the transition from elastic to plastic behavior with a corresponding reduction of stiffness. The level of the maximum load is identified, and the yield plateau and final failure mode are described. There are pronounced differences between the stiffnesses of connections during loading and unloading, respectively, which will be examined and quantified as well.

The paper focuses on an experimental verification of the current design rules. The tests shall elucidate effects of variations of the connection design, for example by applying lateral reinforcement or by using dowels with increased roughness, on the load-bearing behavior. The identified stiffnesses 
and failure loads for a variety of connection design shall enable to identify deficiencies and limits of applicability of the current design rules.

The ratio between side width and dowel diameter (slenderness) is commonly used to describe the failure mode of a connection although not taking into account the actual strength of wood and dowel, respectively. For symmetric steel-to-timber connections, three failure modes can be distinguished by the number of plastic hinges that form in the dowel (Figure 2): The first failure mode occurs in connections of low slenderness where dowel deformations are moderate and plastic deformations only occur in wood. The second failure mode is characterized by a central plastic hinge in the dowel in combination with plastic deformations in wood (intermediate slenderness). Connections of high slenderness additionally show secondary plastic hinges in the dowel.

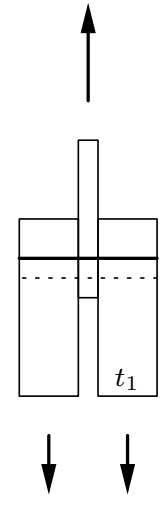

(f)

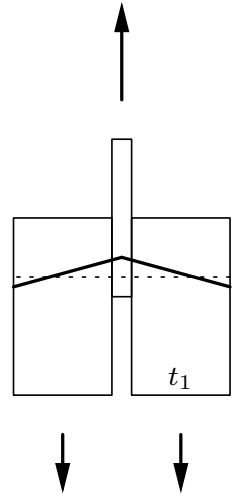

(g)

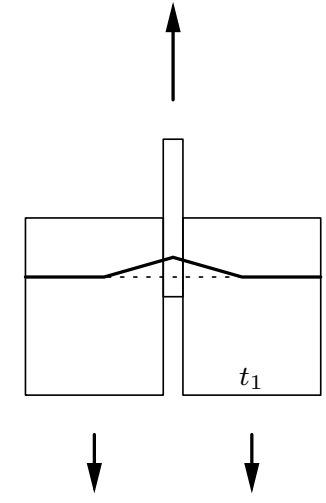

(h)

Figure 2: Failure modes according to EC5 [2] (Numbering according to EC5), depending on the slenderness of the connection

The dimensions of the standard configurations of the dowel connections were chosen such that the appearance of all three failure modes is guaranteed. Other parameters varied in the experimental study are the density of wood, which is one of the main influence factors on the mechanical behavior of a connection, the dowel roughness, which controls the friction between the wood and the dowel, the application of lateral reinforcements for crack prevention, as well as variations of the dimensions of the connections, starting from those of the three standard configurations. 


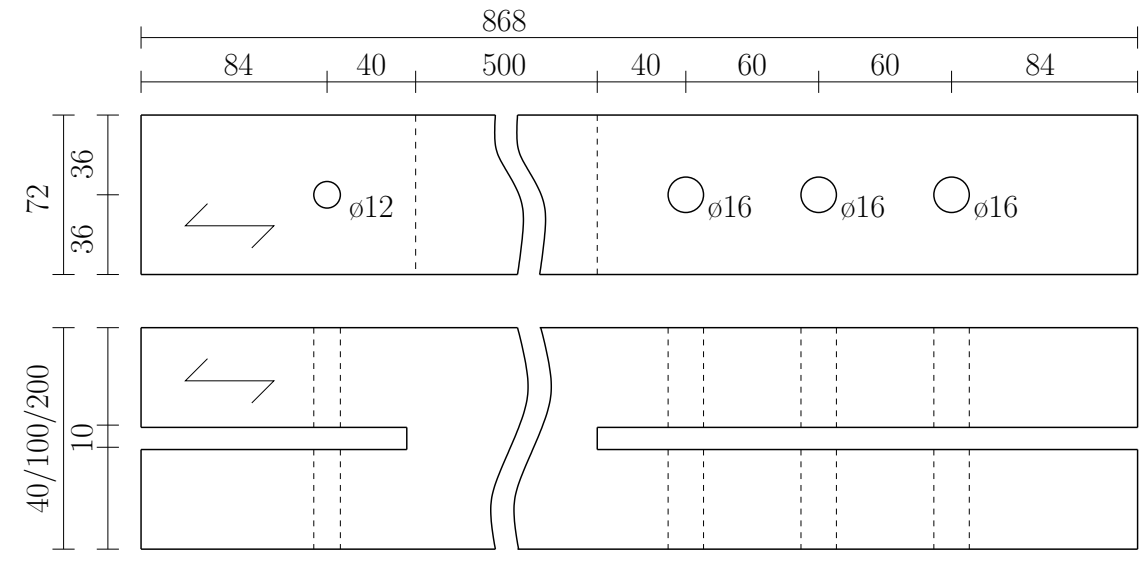

Figure 3: Dimensions [mm] of test specimens

As a secondary aim, the experiments provide valuable data for the purpose of validating numerical simulation models across all load stages.

\section{Materials and methods}

\subsection{Preparation of wood specimens}

The samples were prepared of Norway spruce [Picea abies (L.) H. Karst] taken from a wood trader. The poles were selected for appropriate length and the absence of knots in the area of interest. Four specimens were cut out succeedingly in longitudinal direction, which gives a series with good agreement of morphological and mechanical properties. Depending on the width of the poles, up to four series lying parallel were cut out.

The specimens were cut and planed to standard dimensions for length $(868 \mathrm{~mm})$ and thickness $(72 \mathrm{~mm})$. The specimens were produced in standard widths of 40, 100, and $200 \mathrm{~mm}$, respectively (Figure 3). Variations of the basic geometry were applied later during testing. The slots for the steel sheets were cut out and the holes for the dowels drilled with a pistol grip drill, using an auger drill bit and a guiding device.

The steel plates for the load application were $8 \mathrm{~mm}$ thick and of steel quality S 355. The plates were rough and not coated. The dowels were of $12 \mathrm{~mm}$ diameter, ordered from a manufacturing company specialized on connection tools for timber engineering. The ultimate strength of the dowels was determined in tensions tests according to [18] and amounts to $708 \mathrm{~N} / \mathrm{mm}^{2}$ (mean 
value). The surface of the dowels was smooth in consequence of electrolytical galvanization.

\subsection{Test set-up}

The experimental program comprised tests on 64 specimens, which were grouped into 17 series (Table 1). A series contained four specimens by default, except for four series with only three specimens (Series 02, 05, 05B and 14). Usually, specimens within a series were tested subsequently without changing the loading conditions in order to guarantee similar test conditions, except when the variation was done on purpose.

Table 1: Overview of test series

\begin{tabular}{c|rr|l} 
Series & $\begin{array}{c}\text { Width } \\
{[\mathrm{mm}]}\end{array}$ & $\begin{array}{c}\text { Density } \\
{\left[\mathrm{kg} / \mathrm{m}^{3}\right]}\end{array}$ & Variation \\
\hline 01 & 100 & 485 & \\
02 & 100 & 404 & \\
04 & 100 & 502 & reduced end distance \\
05 & 40 & 419 & \\
05B & 100 & 374 & lateral reinforcement \\
07 & 200 & 402 & \\
08A & 100 & 513 & without unloading cycles \\
08B & 100 & 489 & with lateral reinforcement \\
09A & 40 & 458 & increased dowel roughness \\
10 & 100 & 438 & \\
13 & 100 & 495 & increased dowel roughness \\
14 & 100 & 441 & reduced edge distance \\
15 & 200 & 424 & increased dowel roughness \\
16A & 100 & 384 & \\
16B & 100 & 344 & reduced end distance \\
16C & 100 & 360 & without unloading cycles \\
16D & 100 & 374 & increased dowel roughness
\end{tabular}

The experiments were carried out by means of a Walter \& Bai LFM 150 uniaxial electro-mechanic universal testing machine. Measuring units used were a HBM Spider8 as well as a HBM QuantumX measurement unit, both being combined amplifiers and data acquisition systems, in addition to the measuring unit of the testing machine. 


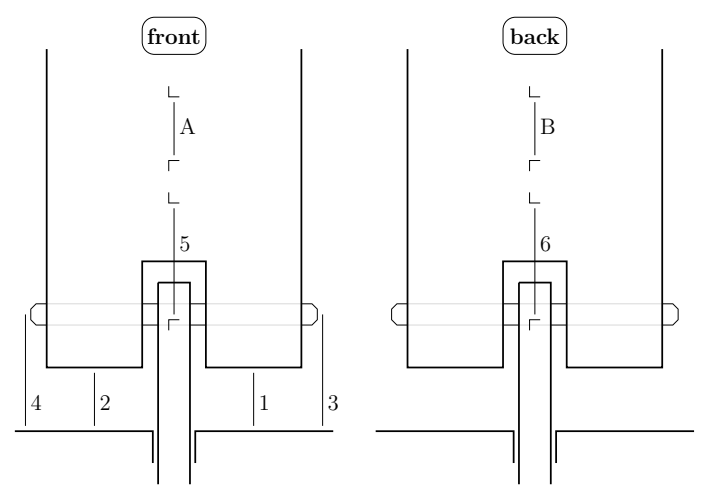

Figure 4: Typical application of measuring equipment; 1 to 6 : inductive displacement transducers HBM WI; A and B: strain transducers HBM DD1

Strain transducers HBM DD1 with a nominal range of $\pm 2.5 \mathrm{~mm}$ and inductive displacement transducers HBM WI with a measuring length of $10 \mathrm{~mm}$ were used to measure displacements, see Figure 4 for their positions. Displacements measured by transducers 1 to 4 and the strains measured by strain transducers $\mathrm{A}$ and $\mathrm{B}$ were used for internal reference only. The results obtained from the transducers 5 and 6 are the basis for the further evaluations. All measurement devices were applied symmetrically to the front and back side or the left and right side, respectively, in order to detect and avoid errors due to rotation or bending of the test set-up.

Right before testing, dimensions and weights of the specimens were measured. The holes were reamed so that the dowels fitted into the holes without applying excessive force. Specimen, plates and dowels were then assembled and placed into the testing machine.

The tests were performed displacement-driven. For most of the tests, unloading cycles at various load levels were carried out. Points of rest of $30 \mathrm{~s}$ duration were chosen at steps of $5 \mathrm{kN}$ for specimens of 100 and $200 \mathrm{~mm}$ wide, and at steps of $2 \mathrm{kN}$ specimens for specimens $40 \mathrm{~mm}$ wide. An initial step of a load of $500 \mathrm{~N}$ with a resting time of $5 \mathrm{~s}$ was included in order to check whether the loading program of the testing machine was active and working properly. Figure 5 shows a typical loading scheme (Specimen 04_1), which is representative for all tests.

Therefore the test program was taking the respective standard for testing dowel-type connections, EN 26891 [19], only as a rough basis. Deviations from the procedure specified in the standard include displacement control 


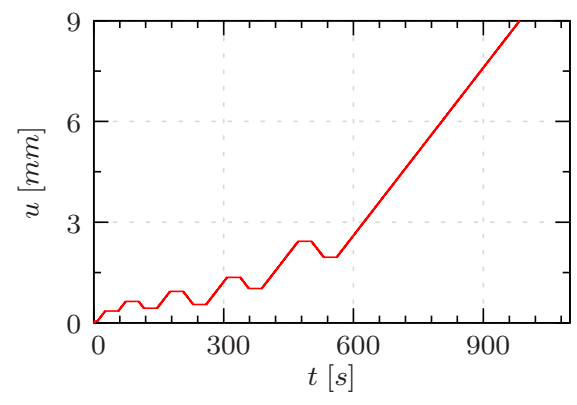

(a) time vs. displacement

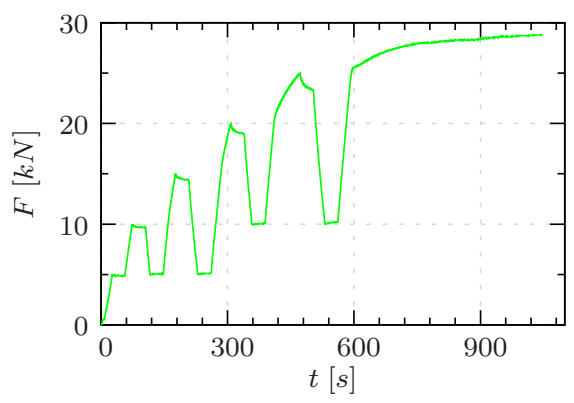

(b) time vs. (responding) force

Figure 5: Typical loading scheme (Specimen 04_1): loading applied displacement-driven at a rate of $1 \mathrm{~mm} / \mathrm{min}$, rests of $30 \mathrm{~s}$ duration

throughout the tests rather than a switch between force and displacement control, the performance of repeated unloading cycles, and the constant loading rate.

\subsection{Test series}

The influence of the loading speed during testing was examined in Series 01 and 02. No effect on the test results was detected within the range of applied loading rates of 0.1 and $2.0 \mathrm{~mm} / \mathrm{min}$. For the remaining tests the rate was fixed to $0.2 \mathrm{~mm} / \mathrm{min}$ for specimens of $40 \mathrm{~mm}$ width, and to $1.0 \mathrm{~mm} / \mathrm{min}$ for specimens of 100 and $200 \mathrm{~mm}$ width, respectively.

The influence of the following parameters was investigated:

- Density: Density varied between 360 and $513 \mathrm{~kg} / \mathrm{m}^{3}$. Its effects were tested in Series 01, 02, 08A, 10, 16A, and 16C on specimens of $100 \mathrm{~mm}$ width.

- Slenderness: The connection behavior at a standard width of $100 \mathrm{~mm}$ was compared to that of specimens of 40 and $200 \mathrm{~mm}$ width (Series 05 and 07 , respectively), for specimens of intermediate density between 402 and $419 \mathrm{~kg} / \mathrm{m}^{3}$.

- Dowel roughness: Series 09A, 13, 15, and 16D were carried out using dowels of increased roughness. The dowels were sanded or engrailed, respectively. The effect of the roughness was investigated for all widths 
(40, 100, $200 \mathrm{~mm})$, whereas density was varied additionally for intermediate slenderness.

- End/edge distance: In Series 16B and 04, the end distance of the dowels was reduced stepwise. Specimens of Series 14 were tested with a stepwise reduced edge distance.

- Reinforcement: Specimens of Series 05, 05B, and 08B were laterally reinforced with the help of clamps. The clamps help to prevent brittle failure in tension perpendicular to the fiber direction during loading and, hence, increase the maximum displacement at failure. Clamps were preferred to screws, which are commonly used in timber engineering, in order to produce a pure lateral restraint without superimposed bending effects of the screws. The reinforcement was attached to specimens of small and intermediate widths, density variation was additionally studied on specimens of intermediate width.

\section{Results}

In the following, test results are presented and, in particular, the influences of the varied parameters on the load-bearing behavior are discussed. Thereby, a sample with standard dimensions and dowel characteristics serves as reference.

The load-displacement-curves shown are plotted for relative displacements between the wooden parts and the steel plate (mean value of results of transducers 5 and 6 in Figure 4). The maximum displacement of $10 \mathrm{~mm}$ that could be measured with the used devices was sometimes not sufficient to monitor the entire load-displacement path up to failure. As a remedy, the displacement transducers were repositioned during some tests, and the results assembled appropriately later.

The load-displacement-curves for all specimens of each series are displayed in Appendix A, Figures A.15(a)-(q), respectively. For better readability, only selected plots are used in some of the following plots.

\subsection{Density}

The density of all the samples varied considerably, between a maximum density of $513 \mathrm{~kg} / \mathrm{m}^{3}$ and a minimum density of $360 \mathrm{~kg} / \mathrm{m}^{3}$, the average being $430 \mathrm{~kg} / \mathrm{m}^{3}$. For the following comparison, all series with a width of $100 \mathrm{~mm}$ and an otherwise standard connection design were considered, i.e. Series 01, 
02, 10, 08A, 16A, and 16C. These series cover the full range of densities with average values according to Table 2. In Figure 6(a), the load-displacement curves for the samples with the minimum and maximum density, respectively, of each series are shown.

\begin{tabular}{c||cccccc}
\multicolumn{1}{c||}{} & \multicolumn{7}{c}{ Series } \\
& 01 & 02 & $08 \mathrm{~A}$ & 10 & $16 \mathrm{~A}$ & $16 \mathrm{C}$ \\
\hline @avg $\left[\mathrm{kg} / \mathrm{m}^{3}\right]$ & 485 & 404 & 513 & 438 & 384 & 360
\end{tabular}

Table 2: Mean densities of all specimens of the test series for analyzing the influence of density

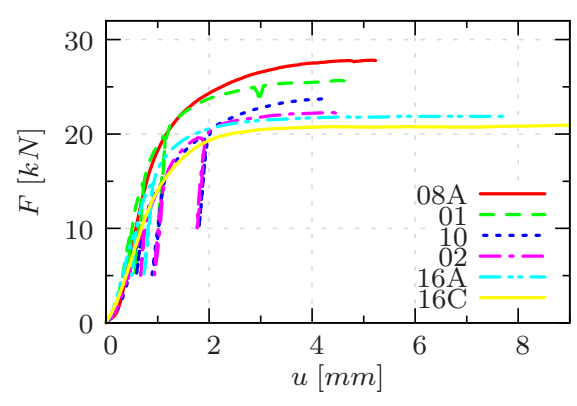

(a) regular

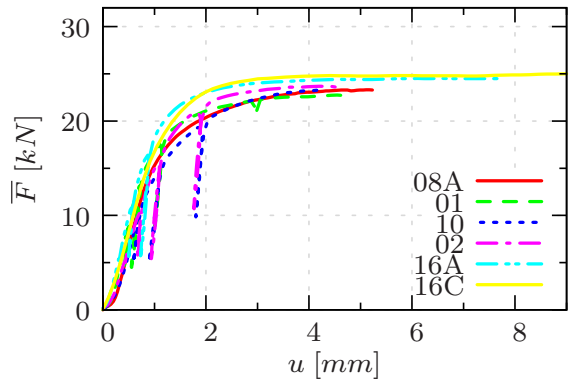

(b) normalized by density

Figure 6: Load-displacement curves for selected specimens of Series 01, 02, 10, 08A, 16A, and 16C $\left(\bar{F}=F \varrho / \varrho_{a v g}\right)$

The pronounced influence of density on the maximum load and on the connection stiffness is clearly visible. Normalizing the curves linearly to the average density $\left(\bar{F}=F \varrho / \varrho_{\text {avg }}\right)$ results in very similar maximum loads for all curves (Figure 6(b)), which underlines the almost linear influence of density on this load-carrying characteristic.

The failure mode according to Johansen is typical for connections of intermediate slenderness: the formation of a single plastic hinge in the symmetry plane of the dowel as well as plastic behavior in the side wood was observed in all specimens.

Furthermore, density affects the load-carrying behavior in a qualitative way: Series with lighter wood tend to show higher displacements at final failure and a longer yield plateau. This is achieved by shearing off and followed 
by considerable displacements in the shear plane, until finally splitting failure occurs. Specimens of dense wood do not show a distinctive yield plateau. Their failure mode is brittle with abrupt failure in the symmetry plane.

The different failure characteristics of light and dense wood result from the considerable influence of density on the behavior of wood under high compression, as they occur in front of the dowel. There, compaction is possible more easily for light wood with a higher percentage of lumens. Dense wood cannot be compacted to a similar extent, and tensile forces in lateral direction lead to splitting failure at high displacements. Regarding stiffness, specimens with higher density are stiffer during first loading, while unloading stiffness is about the same for all densities.

\subsection{Slenderness}

The slenderness of the test specimens was varied in Series 02, 05, and 07, in which all specimens are of comparable densities in the middle range (Table 3). As mentioned in the introduction, the widths were chosen in order to produce the three main ductile failure modes of steel-to-timber dowel connections also considered in EC5, provided that premature splitting failure is excluded. The three different levels of failure loads, associated with different displacements at failure, are clearly distinguishable in Figure 7, which shows load-displacement curves for all series of the three test series.

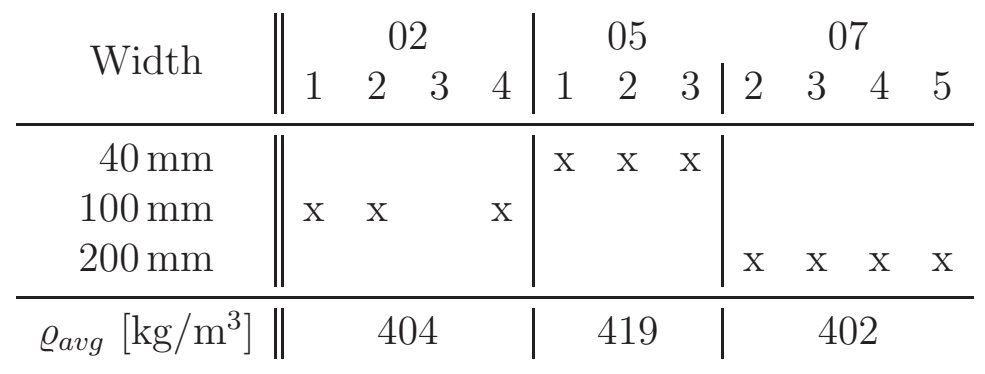

Table 3: Series 02, 05 and 07 with variation of connection width

Depending on the amount of bending of the dowel considerably different contact situations are observed: In connections with a rigid dowel (Series 05), the dowel is in contact with the wood along the full length. This results in maximum utilization in terms of of the thickness-to-load ratio. In connections of intermediate slenderness (Series 02), a single plastic hinge forming in the symmetry plane results in concentration of the contact stresses in the center 


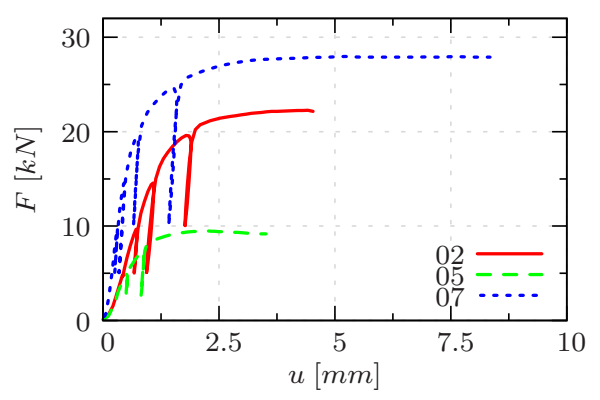

Figure 7: Load-displacement-curves for selected specimens of Series 02, 05, and 07 with different failure modes

and detachment of the unloaded dowel ends from the surrounding wood. In connections of high slenderness (Series 07), the unloaded dowel ends get in contact with the wood opposed to the loaded side, causing back-bending of the dowel and the formation of secondary plastic hinges on both sides of the symmetry plane. A larger contact area is activated that way, and larger forces can be transferred by the connection. The displacements until failure increase significantly with increased width due to the more ductile failure mode and the reduced risk of transverse splitting.

The stiffness during first loading is higher in wide connections, whereas the unloading and the reloading stiffnesses are about the same for all widths. Again, this is because of an enlarged contact area in wide connections.

\subsection{Friction}

As outlined in Section 2.3, the effect of friction between dowel and wood was investigated by using dowels with sanded or engrailed surfaces (Table 4). For the connection type with the standard width of $100 \mathrm{~mm}$, two series were tested with low and with high wood density, respectively. Additionally, a single series was tested also for widths of 40 and $200 \mathrm{~mm}$ for specimens of medium density.

Due to the plastic deformations at the surface induced in the course of the engrailment, the engrailed dowels show a significantly greater outer diameter than the untreated smooth or sanded ones. Accordingly, the holes in the wooden samples were widened manually with the help of rasps. The net cross-section of these dowels, however, was reduced by the engrailment.

The higher friction of the roughened dowels significantly rises the maximum load and the displacements at failure (Figures 8(a), (b)). These figures 


\begin{tabular}{|c|c|c|c|c|c|c|c|c|c|c|c|c|c|c|c|}
\hline \multirow{3}{*}{ Roughness } & \multirow{2}{*}{\multicolumn{4}{|c|}{$\begin{array}{c}40 \mathrm{~mm} \\
09 \mathrm{~A}\end{array}$}} & \multicolumn{8}{|c|}{$100 \mathrm{~mm}$} & \multirow{2}{*}{\multicolumn{3}{|c|}{$\begin{array}{c}200 \mathrm{~mm} \\
15\end{array}$}} \\
\hline & & & & & \multicolumn{4}{|c|}{13} & \multicolumn{4}{|c|}{$16 \mathrm{D}$} & & & \\
\hline & 1 & 2 & 3 & 4 & 1 & 2 & 3 & 4 & 1 & 2 & 3 & 4 & 1 & 2 & 3 \\
\hline Sanded & $\mathrm{x}$ & & & $\mathrm{x}$ & & $\mathrm{X}$ & & $\mathrm{x}$ & & $\mathrm{x}$ & & $\mathrm{x}$ & $\mathrm{X}$ & $\mathrm{x}$ & \\
\hline Engrailed & & & $\mathrm{x}$ & & $\mathrm{x}$ & & $\mathrm{x}$ & & $\mathrm{x}$ & & $\mathrm{x}$ & & & & $\mathrm{x}$ \\
\hline$\varrho_{a v g}\left[\mathrm{~kg} / \mathrm{m}^{3}\right]$ & & 45 & & & & 4 & & & & 3 & & & & 42 & 24 \\
\hline
\end{tabular}

\begin{tabular}{|c|c|c|c|c|c|c|c|c|c|c|c|}
\hline \multirow{2}{*}{ Reference series } & \multicolumn{2}{|r|}{05} & \multicolumn{3}{|c|}{01} & \multicolumn{3}{|c|}{$16 \mathrm{C}$} & \multicolumn{3}{|c|}{07} \\
\hline & 1 & 23 & 1 & 23 & 4 & 1 & 23 & 4 & 1 & 23 & 4 \\
\hline$\varrho_{\text {avg }}\left[\mathrm{kg} / \mathrm{m}^{3}\right]$ & & 419 & & 485 & & & 360 & & & 402 & \\
\hline
\end{tabular}

Table 4: Series with increased dowel roughness

show load-displacement curves for Series 13 and 16D (both using specimens $100 \mathrm{~mm}$ wide) as well as of reference series with smooth dowels. The results confirm the expected effects of increased dowel roughness on the connection behavior, namely a significant rise of both maximum load and maximum displacement at failure. The impact is more pronounced in dense wood (Series 13) than in light wood (Series 16D), where the high compactibility of the wood already results in a very ductile behavior of the connection.

Unlike the behavior observed for the small and medium width samples, no differences were found between the use of engrailed or roughened dowels in Series 15 for the samples with a width of $200 \mathrm{~mm}$ (Figure 8 (d)). All specimens could withstand displacements higher than $10 \mathrm{~mm}$, where the displacement measurement was stopped prematurely before failure occurred.

When using smooth dowels, the width of the contact zone is only approximately half of the diameter of the dowels, resulting in a wedge-like action of the dowel. High tensile stresses in lateral direction will lead to splitting failure at low force and particularly at low displacements, and a characteristic brittle fracture occurs. Rough dowels reinforce the curved wood surface. They contribute to reducing lateral tensile stresses and to widening the contact area. Shear stresses are increased, and the maximal shear stresses occur at a greater distance from the symmetry plane of the connection. The combination of these effects leads to a higher load-carrying capacity and - because of the more ductile failure mode - higher displacements until failure.

The change of the failure mode from brittle to ductile in case of roughened 
dowels is confirmed by the observed fracture pattern. The high shear stresses evoked by the rough dowels lead to failure in the shear plane which is located nearly tangentially to the hole. Wood ruptures in the shear plane and is then crushed due to compression under the dowel. Lateral tension stresses, which could cause brittle, premature failure, do not develop in the symmetry plane.

The engrailed dowels are bent to a high degree so that, due to indentation, a significant tension force can be transferred in the direction of their axis in addition to the shear forces. This explains the considerable increase of the failure load of engrailed dowels beyond that achieved with sanded dowels.

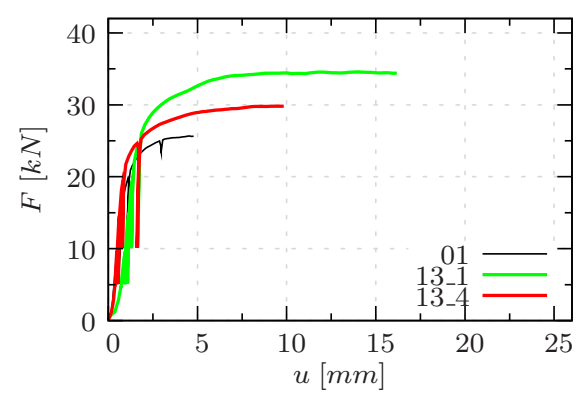

(a) Series 13 (100 mm, high density)

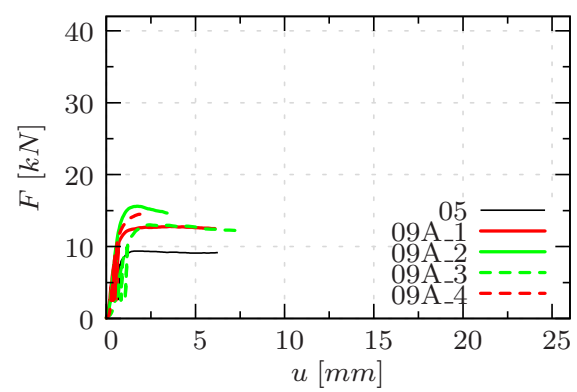

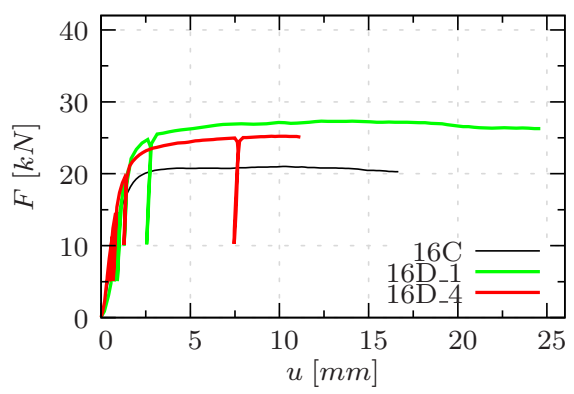

(b) Series 16D (100 mm, low density)

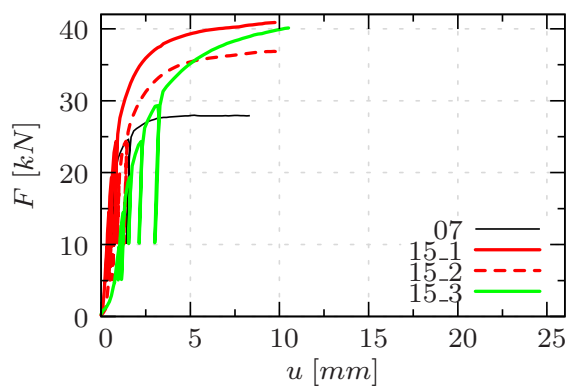

(c) Series 09A (40 mm, medium density)(d) Series 15 (200 mm, medium density)

Figure 8: Load-displacement curves for selected specimens of Series 13, 16D, $09 \mathrm{~A}^{1}$ and 15 with increased dowel roughness

\footnotetext{
${ }^{1}$ During testing of Specimen 09A_2, a machine error occurred, so that further testing until failure was not possible. Specimen 09A_4 failed prematurely before reaching the yield plateau.
} 


\subsection{End distance}

The standard end distance of the dowels in the specimens was $84 \mathrm{~mm}$, seven times the dowel diameter $d$, which is in line with the minimum end distance required in EC5. In Series 04 and 16B, the end distance of the samples with a width of $100 \mathrm{~mm}$ was reduced successively from this value to a minimum of $30 \mathrm{~mm}(2.5 d)$ in steps of $18 \mathrm{~mm}(1.5 d)$ (Table 5 ).

\begin{tabular}{|c|c|c|c|c|c|c|c|c|}
\hline \multirow{3}{*}{ End distance } & \multicolumn{8}{|c|}{$100 \mathrm{~mm}$} \\
\hline & \multicolumn{4}{|c|}{04} & \multicolumn{4}{|c|}{$16 \mathrm{~B}$} \\
\hline & 1 & 2 & 3 & 1 & 1 & 2 & 3 & 4 \\
\hline $84 \mathrm{~mm}(7.0 d)$ & $\mathrm{x}$ & & & & $\mathrm{x}$ & & & \\
\hline $66 \mathrm{~mm}(5.5 d)$ & & $\mathrm{x}$ & & & & & & $\mathrm{x}$ \\
\hline $48 \mathrm{~mm}(4.0 d)$ & & & $\mathrm{x}$ & & & & $\mathrm{X}$ & \\
\hline $30 \mathrm{~mm}(2.5 d)$ & & & & & & $\mathrm{x}$ & & \\
\hline$\varrho_{a v g}\left[\mathrm{~kg} / \mathrm{m}^{3}\right]$ & & 50 & & & & & & \\
\hline
\end{tabular}

Table 5: Series 04 and 16B with specimens showing reduced end distance of dowel

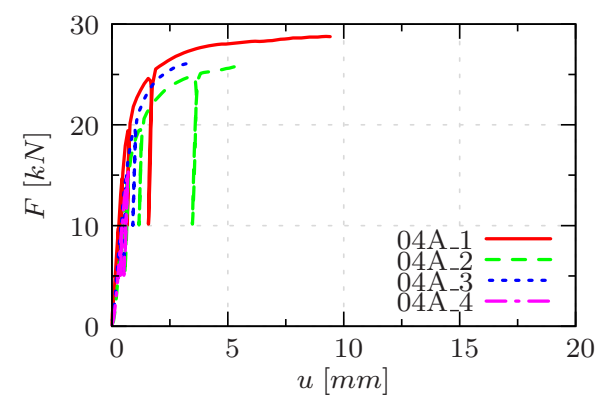

(a) Series 04 (100 mm, high density)

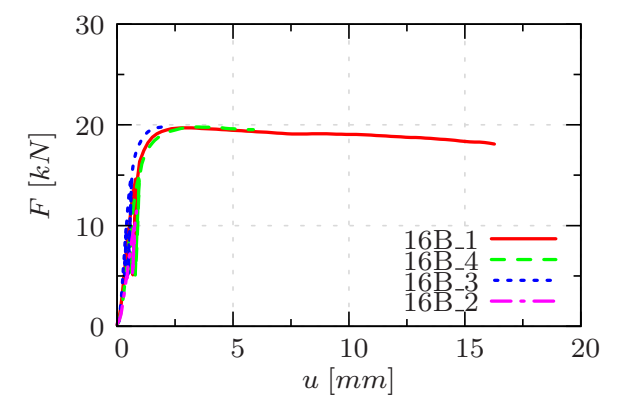

(b) Series 16B (100 mm, low density)

Figure 9: Load-displacement curves for all specimens of Series 04 and 16B with reduced end distance

A reduced end distance significantly reduces the maximum displacement (Figures 9(a),(b)), while the course of the load-displacement curves and the stiffnesses are not affected. Overly severe shortening results in reduced maximum load, since then the increased tension stresses in the specimens in front of the dowel can lead to premature splitting failure. 


\subsection{Edge distance}

The edge distance of the regular specimens was set to $36 \mathrm{~mm}(3 \mathrm{~d})$, again in line with the minimum edge distance according to EC5. This results in a total net thickness for transferring loads of $60 \mathrm{~mm}(5 d)$. In Series 14, the edge distance was reduced successively in steps of $6 \mathrm{~mm}(0.5 d)$ to $18 \mathrm{~mm}$ $(1.5 d)$ (Table 6).

\begin{tabular}{c||cccc}
\multicolumn{1}{c||}{} & \multicolumn{4}{c}{$100 \mathrm{~mm}$} \\
Edge distance & 1 & 2 & 3 & 4 \\
\hline $30 \mathrm{~mm}(2.5 d)$ & $\mathrm{x}$ & & \\
$24 \mathrm{~mm}(2.0 d)$ & & & $\mathrm{x}$ & \\
$18 \mathrm{~mm}(1.5 d)$ & & & $\mathrm{x}$ \\
\hline$\varrho_{\text {avg }}\left[\mathrm{kg} / \mathrm{m}^{3}\right]$ & & 441 & \\
& & & & \\
& & & & \\
& & & & \\
reference series & 1 & 2 & 3 & 4 \\
\hline & $\varrho_{\text {avg }}\left[\mathrm{kg} / \mathrm{m}^{3}\right]$ & & .438 &
\end{tabular}

Table 6: Series 14 with samples with reduced edge distance of dowel

The observed load-displacement curves do not vary significantly for the different edge distances (Figure 10). Apparently, even the considerably reduced edge distance of $1.5 d$ was sufficient to guarantee secure load transfer.

A bigger influence of the edge distance on the failure load had been assumed, since the pronounced anisotropy of wood with a very high stiffness in the fiber direction restricts transverse load distribution and, thus, load transfer to the outer parts of the connection. The stress concentrations around the hole seem to be lower than expected.

\subsection{Lateral reinforcement}

In Series 05, 05B, and 08B, some of the specimens were tested with a lateral reinforcement (Table 11). Clamps were applied as external reinforcement, mimicking screws usually used as reinforcement in structural timber engineering but preventing the influence of bending effects of screws. 


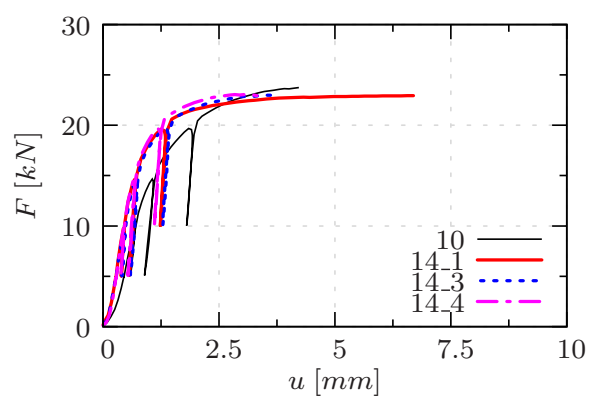

Figure 10: Load-displacement-curves for all specimens of Series 14 with reduced edge distance

\begin{tabular}{|c|c|c|c|c|c|c|c|c|c|c|}
\hline & \multicolumn{3}{|c|}{$40 \mathrm{~mm}$} & \multicolumn{3}{|c|}{$\begin{array}{c}100 \mathrm{~mm} \\
08 \mathrm{~B}\end{array}$} & \multicolumn{4}{|c|}{$\begin{array}{c}100 \mathrm{~mm} \\
05 \mathrm{~B}\end{array}$} \\
\hline & 1 & 2 & 3 & 1 & 2 & 3 & 4 & 1 & 2 & 3 \\
\hline $\begin{array}{l}\text { Lateral reinforcement } \\
\text { W/o reinforcement }\end{array}$ & & $\mathrm{x}$ & $\mathrm{x}$ & $\mathrm{x}$ & $\mathrm{x}$ & $\mathrm{x}$ & $\mathrm{x}$ & $\mathrm{X}$ & $\mathrm{x}$ & $\mathrm{X}$ \\
\hline$\varrho_{a v g}\left[\mathrm{~kg} / \mathrm{m}^{3}\right]$ & & 419 & & & & & & & 374 & \\
\hline
\end{tabular}

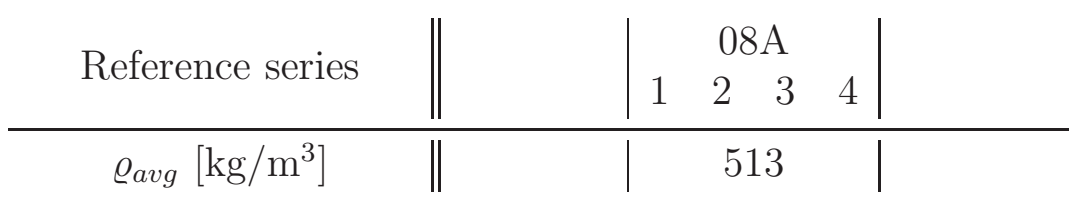

Table 7: Series 05 and 08B with lateral reinforcement

The load-displacement curves of Series $05(40 \mathrm{~mm})$ do not show significant differences regarding stiffness and maximum load (Figure 11(a)) but the displacements at failure are clearly higher for the reinforced Specimen 05_3. The lateral reinforcement retains lateral splitting, which enables to reach larger displacements and, thus, results in a more ductile behavior of the connection. It does not, however, increase the overall loading capacity of the connection. Respective gains in displacement amount to up to $50 \%$ in Series 08B with specimens of high density and to 50\%-250\% in Series 08B

\footnotetext{
${ }^{2}$ Due to a machine-error, the test of Specimen 05_3 had to be stopped before failure occurred. Most likely an even higher displacement could have been reached.
} 


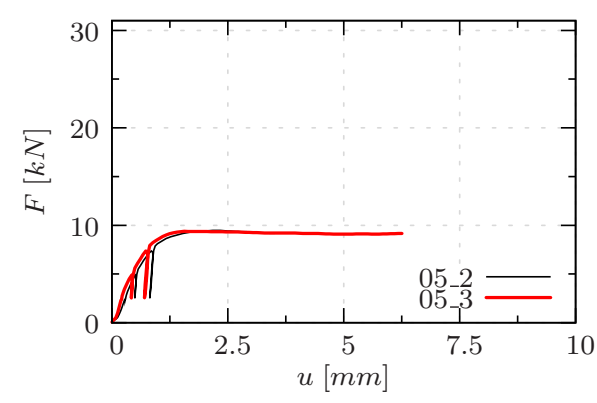

(a) Series $05(40 \mathrm{~mm})$

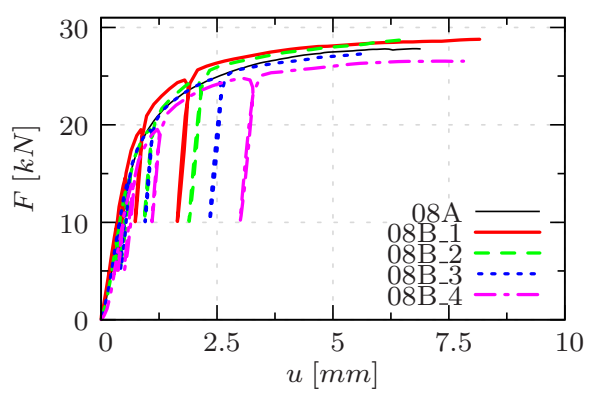

(b) Series 08B (100 mm)

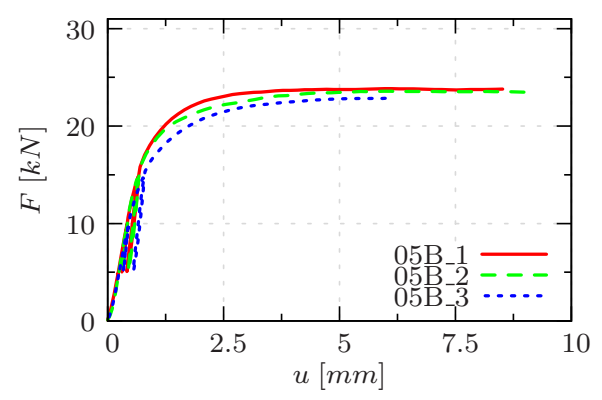

(c) Series 05B (100 mm)

Figure 11: Load-displacement-curves for selected specimens of Series $05^{2}$, 05B, and 08B with lateral reinforcement

with specimens of medium density. The efficiency of a lateral reinforcement in wood of high density is limited, since at high loads the resulting splitting forces can exceed the load-carrying capacity of the reinforcement.

In Series 05B, only Specimen 05B_2 failed by lateral splitting in the symmetry plane, which was the expected failure mode. Specimens 05B_1 and 05B_3 split longitudinally in the clear wood section, which is a failure mode not commonly described.

\section{Discussion}

\subsection{Typical loading behavior}

A wide variation of different set-ups and specimen properties was examined and resulted in very different failure loads and displacements. Nevertheless, except for outliers, all load-displacement curves show the same 
characteristic shape, and typical loading phases observed in all tests can be identified as marked in Figure 12.

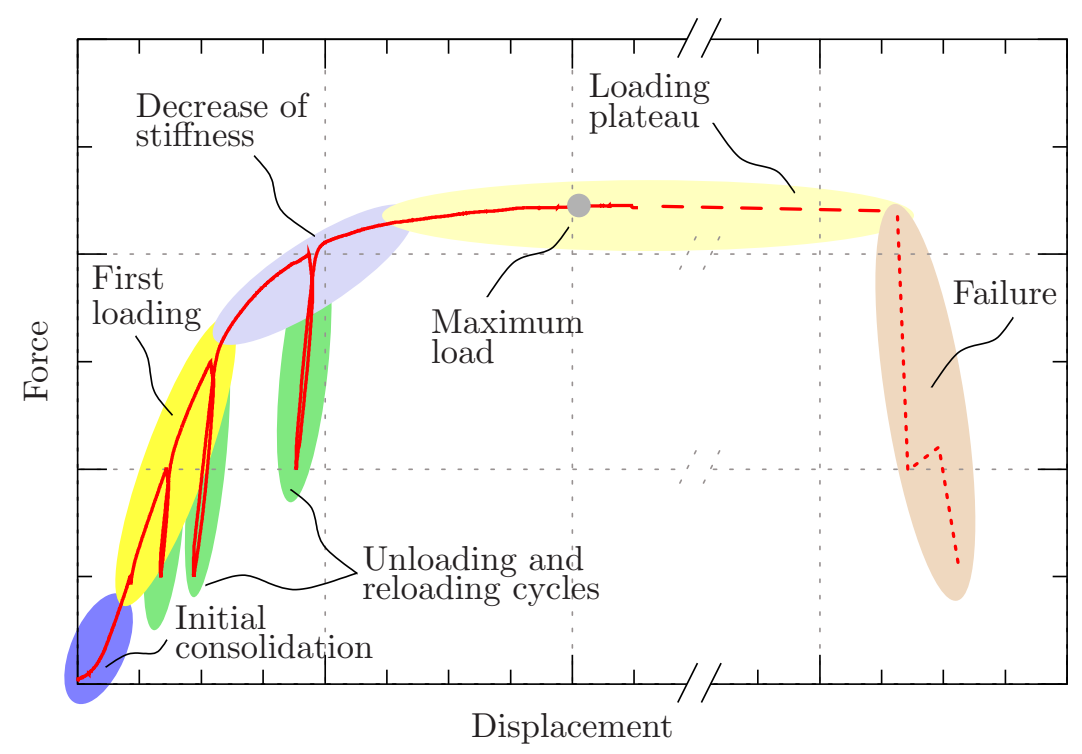

Figure 12: Individual loading phases of a typical dowel-type connection

Initial consolidation. The connections tested showed very low stiffness at the beginning of the loading process. Maximum stiffness was not reached until a significant load and displacement were applied.

This low stiffness is probably caused by imperfect contact between dowel and wood, which results from geometric roughness of the specimen in the contact zone as well as from imperfections of the contact surfaces. As regards the former, the axis of the bore-hole may not be drilled perfectly straight but with some curvature, and/or it may not be in exact right angles to the loading plane. The surface conditions of the dowel and the wood specimen affect the establishment of the load transmission. Depending on the drilling tool, the drilling speed, the wear of the tool, etc., the wood surface is not plane. It rather exhibits for example some waviness, as early wood and late wood are cut differently, or some roughness, as the fibers are not cut perfectly but in a frazzled manner. The effects of the quality of the surface of the bolt-hole on the load-deformation characteristics are described by Soltis [20] in detail.

Both, geometric and surface imperfections, lead to a softer connection stiffness at the beginning of the loading, as the contact between wood and 
dowel is not yet fully established. It is assumed, that the consolidation process occurs over the total length of the dowel simultaneously in connections of low slenderness. In connections of intermediate and high slenderness, the contact area evolves continuously during increasing load due to the progressive bending of the dowel.

First loading. This term refers to the phase which directly follows the consolidation process, and in which the maximum stiffness during first loading (as distinguished from un- and reloading stiffness) of the connection is reached. Also in this region, a non-linear course of the load-displacement curve is observed in most tests, and an approximation by a straight line is only possible over short sections. Perfect linearity cannot be expected, since consolidation is still ongoing (especially in wider specimens), and the material behavior of the wood starts to be nonlinear (plasticity in compression). The smaller the region of initial consolidation, the more reliably a linear region of maximum first loading stiffness can be expected (cf. Series 16A).

Unloading and reloading cycles. The stiffness in unloading and reloading cycles significantly exceeds the maximum stiffness during first loading. Unlike the first loading, the un- and reloading cycles show an approximately linear elastic behavior. The deformations upon the consolidation in the contact area and the plastic deformations of the wood matrix do not recede, and the wood does not deform back to its initial form and behaves linearly.

During reloading, the dowel perfectly fits the surrounding wood, and no further adaption resulting in permanent deformations occur. The reloading path follows the unloading path, showing a considerably higher stiffness than during first loading, up to the previously achieved maximum load level. When the specimen is loaded further beyond this level, and the displacements exceed the level reached before unloading, the loading curve bends, and the curve continuous along the course of the first loading.

An identical behavior and equal stiffnesses during unloading and reloading were observed for all variations and all load stages, also regardless of the basic density or of the width of the specimens (see Section 4.2).

Decrease of stiffness, yield plateau. During further loading, the stiffness decreases dramatically, and the maximum load is reached. This decrease is caused by reaching the compression strength in parts of the wood matrix and the growth of the plastic deformations. Additionally, plastic hinge(s) form in 
the dowel in connections with intermediate and high slenderness. The maximum load level and the ductility (i.e. the displacement until failure) depend significantly on e.g. density, frictional behavior, and lateral reinforcement.

Displacements until final failure differ considerably; in some specimens (e.g. specimens of very dense wood) the yield plateau was hardly reached at all. On the other hand, displacements were up to over $20 \mathrm{~mm}$ in soft specimens (e.g. Series 16D). Lateral reinforcement allowed to reach such levels of displacement also for specimens of medium densities. In case of an extensive yield plateau, brittle failure in the local wood matrix occurs (shear failure), which, however, does not affect the ductile behavior on a global level. Thus, shear failure is actually a necessity for a high ductility of dowel-type connections.

Failure. The last stage in the load-displacement-diagrams is final failure, which occurs spontaneously and results in a sudden load drop. The failure mode differs in respect of the same parameters as mentioned before in relation to the maximum load level, namely density, friction, and lateral reinforcement. The following failure modes were observed (failure planes are highlighted in Figure 13):

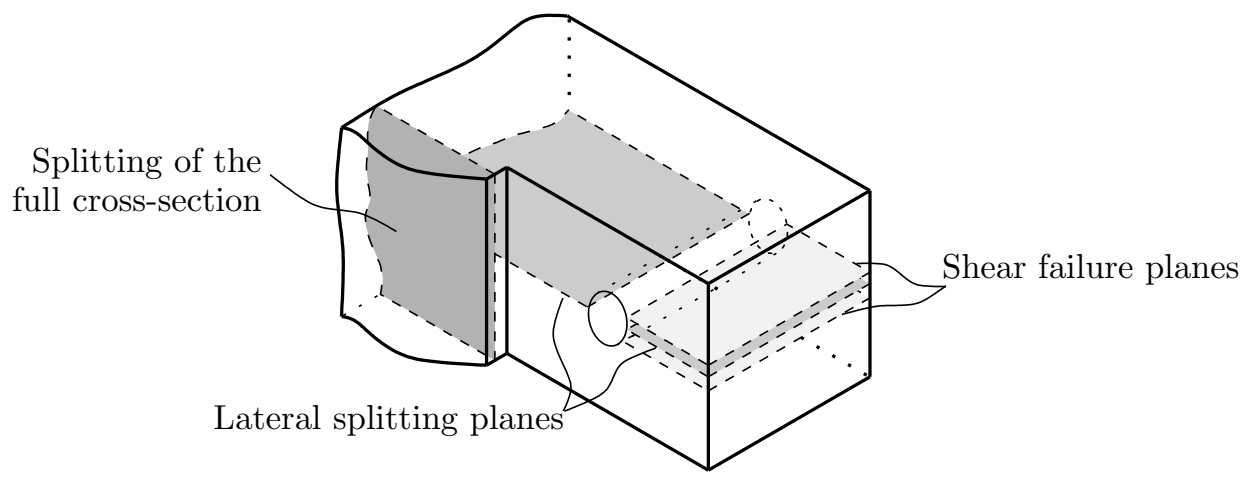

Figure 13: Observed failure modes

Lateral splitting occurs at low friction between wood and dowel and high wood density. It is a highly brittle failure mode caused by high tensile forces normal to the symmetry plane of the connection through the dowels axis. The final fracture surface need not follow the annual ring pattern, which marks the transitions between lighter, weaker early wood and denser, stronger late wood. 
Shear failure generally occurs in combination with tensile stresses in lateral direction. The failure planes are parallel to the symmetry plane of the connection through the dowels axis, at a distance of about twothirds of the dowel radius. In principle, shear failure is a brittle failure mode, which nevertheless leads to ductile failure at the global level as described before.

Shear failure was observed in specimens with high friction between dowel and wood and in connections with lateral reinforcement. It occurs in cases where lateral splitting is prevented. Cracks do not propagate throughout the wood section, as shear stresses are highly dissipative, and high displacements can be reached before final failure occurs.

When an extensive yield plateau has developed upon local shear failure, lateral splitting is the final failure mode. Failure planes are then identical with the shear planes.

Splitting of the full cross section is the final failure mode when lateral splitting is prevented. Again, local shear failure occurs first, allowing large deformations and resulting in a globally ductile behavior. Finally, the highly bent dowel drives the wooden sections apart, so that tensile forces develop in the full cross section in the lateral part of the connection, acting on a plane normal to the dowel after the end of the slot.

\subsection{Comparison to EC5}

In the following, the results of the experiments are compared to the current generation of European standards with respect to stiffness, ultimate load, and failure mode, as well as to influences of density and other parameters. The comparison shall give indications about the reliability and efficiency of the current design formulae and elucidate influences so far not captured (appropriately) by the formulae.

Table 8 provides the projected design values for strength and stiffness of all test series according to EC5. These design values are also specified for samples of average density and the three investigated widths. They will serve for normalizing the test results in the following.

Stiffness. Stiffness in the Serviceability Limit State (SLS) is estimated by $K_{\text {ser }}=\varrho_{m}^{1.5} d / 23$, with $K_{\text {ser }}$ in $\mathrm{N} / \mathrm{mm}$, where $\varrho_{m}$ is the density of the wood 
Table 8: Comparison of design strength, $F_{v, R k}$, and stiffness, $K_{\text {ser }}$, according to EC 5, for each experimental series

\begin{tabular}{|c|c|c|c|c|}
\hline Series & $\begin{array}{l}\text { Width } \\
{[\mathrm{mm}]}\end{array}$ & $\begin{array}{l}\text { Density } \\
{\left[\mathrm{kg} / \mathrm{m}^{3}\right]}\end{array}$ & $\begin{array}{c}F_{v, R k}(\mathrm{EC} 5) \\
{[\mathrm{kN}]}\end{array}$ & $\begin{array}{c}K_{\text {ser }}(\mathrm{EC} 5) \\
{[\mathrm{kN} / \mathrm{mm}]}\end{array}$ \\
\hline 05 & 40 & 419 & 10.9 & 17.9 \\
\hline 09A & 40 & 458 & 11.9 & 20.5 \\
\hline 01 & 100 & 485 & 23.6 & 22.3 \\
\hline 02 & 100 & 404 & 20.9 & 16.9 \\
\hline 04 & 100 & 502 & 24.1 & 23.5 \\
\hline 05B & 100 & 374 & 19.9 & 15.1 \\
\hline $08 \mathrm{~A}$ & 100 & 513 & 24.5 & 24.2 \\
\hline 08B & 100 & 489 & 23.7 & 22.6 \\
\hline 10 & 100 & 513 & 24.5 & 24.2 \\
\hline 13 & 100 & 495 & 23.9 & 23.0 \\
\hline 14 & 100 & 441 & 22.1 & 19.3 \\
\hline $16 \mathrm{~A}$ & 100 & 384 & 20.2 & 15.7 \\
\hline $16 \mathrm{~B}$ & 100 & 344 & 18.9 & 13.3 \\
\hline $16 \mathrm{C}$ & 100 & 360 & 19.4 & 14.3 \\
\hline $16 \mathrm{D}$ & 100 & 374 & 19.9 & 15.1 \\
\hline 15 & 200 & 424 & 32.5 & 18.2 \\
\hline 07 & 200 & 402 & 31.4 & 16.8 \\
\hline$\varrho_{a v g}$ & 40 & 430 & 11.2 & 18.6 \\
\hline$\varrho_{a v g}$ & 100 & 430 & 21.8 & 18.6 \\
\hline$\varrho_{a v g}$ & 200 & 430 & 32.7 & 18.6 \\
\hline
\end{tabular}

in $\mathrm{kg} / \mathrm{m}^{3}$ and $d$ the dowel diameter in $\mathrm{mm} . K_{\text {ser }}$ is valid for a connection with a single shear plane and a single dowel and was actually derived for wood-wood-connections. When applied to steel-to-timber connections, as considered in this manuscript, $K_{\text {ser }}$ should therefore to be multiplied by 2.0 as suggested in EC5.

In the Ultimate Limit State (ULS), stiffness is reduced to two thirds of $K_{\text {ser }}$, so that $K_{u}=2 / 3 K_{\text {ser }}$, with $K_{u}$ in $\mathrm{N} / \mathrm{mm}$. Both formulae for stiffnesses are empirically derived formulae.

Figure 14 compares stiffnesses observed in the experiments (the unloading stiffness was determined by a linear fitting of the unloading path of the experiments) with corresponding design stiffnesses according to EC5 for specimens 
of $100 \mathrm{~mm}$ width and varying density. For this purpose, lines with a slope equal to the design stiffness are included into plots of the measured loaddisplacement curves of the series used for studying the density influence (see Section 3.1). Specimens with higher density tend to exhibit higher stiffnesses during initial loading, which is accurately predicted by EC5. Unloading stiffness is about the same for all densities $(\approx 55 \mathrm{kN} / \mathrm{mm})$ and significantly higher than initial loading stiffness.

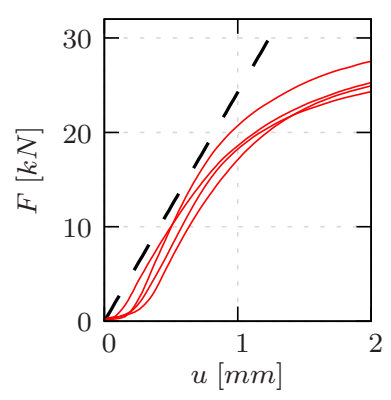

(a) Series $08 \mathrm{~A}$

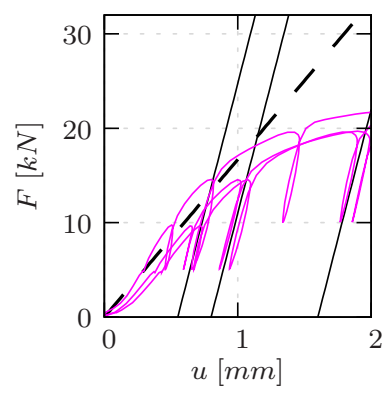

(d) Series 02

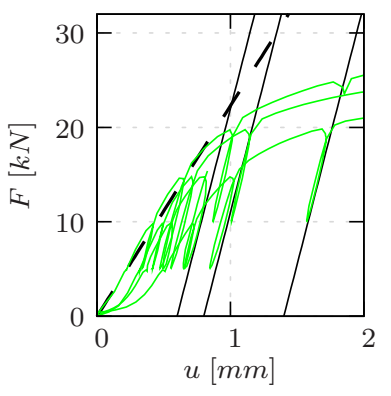

(b) Series 01

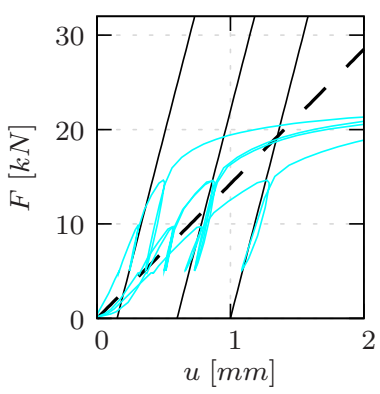

(e) Series $16 \mathrm{~A}$

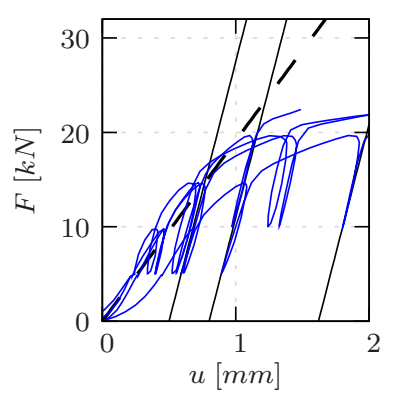

(c) Series 10

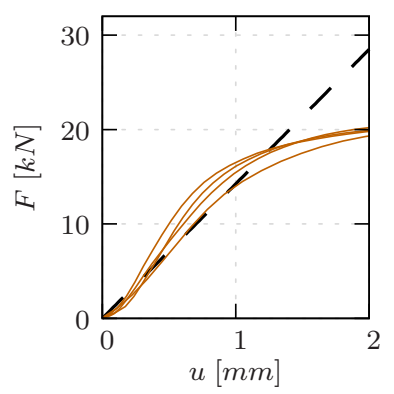

(f) Series 16C

Figure 14: Details of load-displacement curves of $100 \mathrm{~mm}$ wide specimens of Series 08A, 01, 10, 02, 16A and 16C (sorted by descending average density of all specimens): respective stiffness according to EC5 (dashed lines), approximated stiffness for un- and reloading (black lines, $55 \mathrm{kN} / \mathrm{mm}$ for all specimens)

Only for specimens with a width of $100 \mathrm{~mm}$ (Figures 14 and 15 (b)) the stiffnesses specified by EC5 are appropriate. In narrow and wide connections, the EC5 formulae underestimates or overestimates the observed stiffnesses, respectively (Figures 15(a) and (c)). The formulae for stiffness estimation do not cover the influence of connection width, for example by differentiation of 


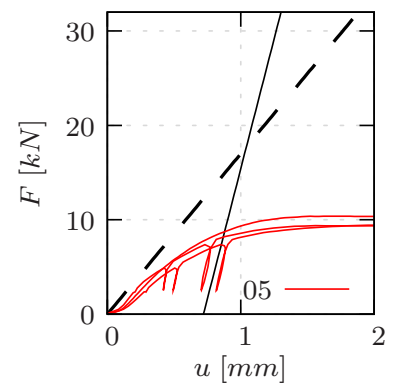

(a) Specimens with width of $40 \mathrm{~mm}$

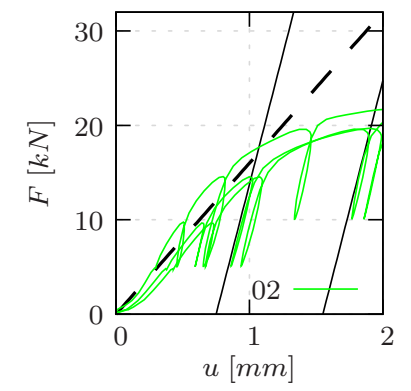

(b) Specimens with width of $100 \mathrm{~mm}$

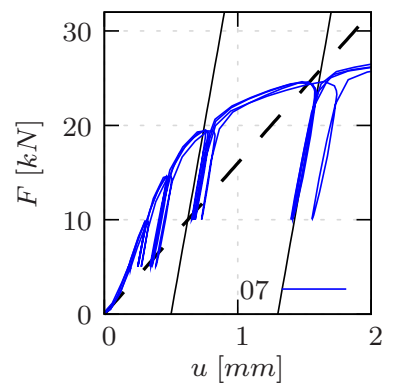

(c) Specimens with width of $200 \mathrm{~mm}$

Figure 15: Comparison of experimentally determined stiffnesses of selected tests with corresponding design values from EC5 for different widths: respective stiffness according to EC5 (dashed lines), approximated stiffnesses for unloading and reloading (black lines, $55 \mathrm{kN} / \mathrm{mm}$ for all specimens with widths of 40 or $100 \mathrm{~mm}, 80 \mathrm{kN} / \mathrm{mm}$ for specimens with widths of $200 \mathrm{~mm}$ )

possible failure modes, like it is done in strength design.

Strength. The characteristic load-carrying capacity $F_{v, R k}$ (in N) of a single shear plane in a dowel connection according to EC5 [2] follows from

$$
F_{v, R k}=\min \left\{\begin{array}{l}
f_{h, 1, k} t_{1} d \\
f_{h, 1, k} t_{1} d\left[\sqrt{2+\frac{4 M_{y, R k}}{f_{h, 1, k} d t_{1}^{2}}}-1\right] \\
2.3 \sqrt{M_{y, R k} f_{h, 1, k} d}
\end{array}\right.
$$

where (f), (g), and (h) denote the three characteristic failure modes (see Figure 2). The minimum of $F_{v, R k}$ is always decisive. Mode $f$ describes connections with a rigid dowel, $g$ and $h$ describe connections of intermediate and high slenderness, respectively.

In the formulae, $\varrho_{k}$ is the characteristic density of the wood in $\mathrm{kg} / \mathrm{m}^{3}$, $t_{1}$ the width of the wooden part in $\mathrm{mm}, f_{h, 1, k}=0.082(1-0.01 d) \varrho_{k}$ the characteristic embedment strength in $\mathrm{N} / \mathrm{mm}^{2}, d$ the dowel diameter in $\mathrm{mm}$, $f_{u, k}$ the characteristic tensile strength of the dowel in $\mathrm{N} / \mathrm{mm}^{2}$, and $M_{y, R k}=$ $0.3 f_{u, k} d^{2.6}$ the characteristic plastic moment of the dowel in Nmm. The inconsistency of the units in the formulae underlines their (to a large extent) 
empirical origin. There are no restriction on the maximum allowable displacements, and plastic deformations are allowed without limits. Effects of lateral reinforcement or increased friction between wood and dowel are not taken into account. For determining values in Table 8, the tensile strength is $f_{u, k}=708 \mathrm{~N} / \mathrm{mm}^{2}$. The width $t_{1}=(2 a-10) / 2$ is half of the width of the wood net-section (see Figure 3 for dimensions).

In the formulae of EC5, most of the influences studied in the experiments are covered by the embedment strength $f_{h, 1, k}$, which linearly depends on density. Additionally, the friction between dowel and wood as well as a reduction of end length affect the embedment strength. A variation of the connection slenderness is captured by the direct influence of the dowel diameter $d$ and the side width $t_{1}$.

Figures 16(a) to (c) re-illustrate the test results, now classified according to the connection slenderness. The shown forces are normalized to $\varrho_{\text {avg }}=$ $430 \mathrm{~kg} / \mathrm{m}^{3}\left(\bar{F}=F \varrho / \varrho_{\text {avg }}\right)$ by means of the data included at the bottom of Table 8 . The figures clearly show the influence of various parameters on the ultimate loads.

The comparison of the experimental results with the design values indicates that the design values are conservatively determined for connections with intermediate slenderness, values for $\mathrm{F}_{v, R k}$ are equal or below the experimental values. In connections with a rigid dowel, the design value overestimate the measured connection strength in Series 05 in some specimens. Very similar results are found in connections of high slenderness where the strength is underestimated for the standard configuration. The figures show that a distinctively higher load than given by the design formulae by up to $40 \%$ can be achieved with engrailed dowels (Specimens 09A_2, 13_1, 15_3, 16D_1) or lateral reinforcement (Specimen 05B_1).

\section{Conclusions}

A comprehensive test series on single-dowel steel-to-timber connections was carried out in order to build the required knowledge and database for an improved connection design in timber engineering. The tests delivered insight into the effects of geometric and material parameters on the load-carrying characteristics. Distinctively different domains were described: initial consolidation, first loading, unloading and reloading cycles, ductile yield plateau, and failure modes. 


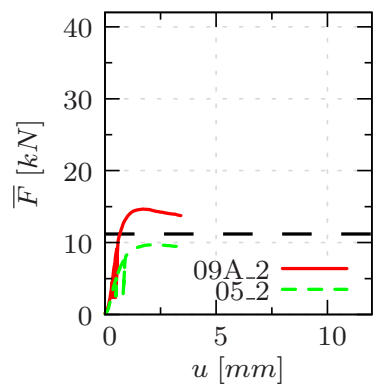

(a) Samples with width of $40 \mathrm{~mm}$

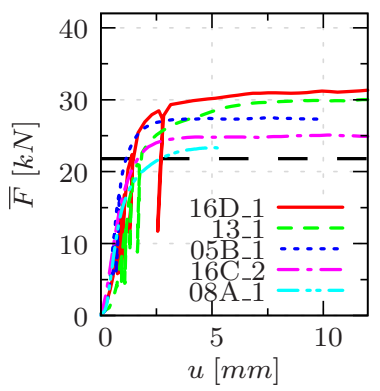

(b) Samples with width of $100 \mathrm{~mm}$

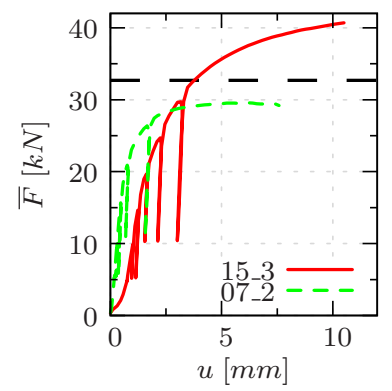

(c) Samples with width of $200 \mathrm{~mm}$

Figure 16: Comparison of strength of selected tests with design values from EC5 (normalized linearly to $\varrho_{\text {avg }}=430 \mathrm{~kg} / \mathrm{m}^{3} ; \bar{F}=F \varrho / \varrho_{\text {avg }}$ )

The comparison of the experiments with the current state of design in structural timber engineering in EC5 shows partially good agreement of the design values with the test results. The distinction between the failure modes with the absence or creation of plastic hinge(s) is in accordance with EC5. Design strength was found to be conservatively defined for intermediate slenderness. In connections of low as well as high slenderness the design values partially overestimated the actual experimental strengths. The positive effects of increased dowel roughness and lateral reinforcement, which are not covered by the current design rules, were shown in the tests. An increase of ultimate load and an extension of the ductile yield plateau as well as improved resistance against splitting failure is possible. A variation of the connection stiffness following the later failure mode (Johansens classification according to the number of plastic hinges in the dowel) is clearly observed in the experiments.

In EC5, the connection width is not taken into account when determining stiffness. Design stiffness is therefore clearly determined with insufficient accuracy and might lead to unreliable results in static design. Furthermore, the design rules do not consider the varying stiffness of first loading and (repeated) unloading and reloading during the life-span of a structure. A suitable concept for assessing stiffness should be introduced in order to represent the nonlinear behavior during loading up to the Ultimate Limit State. This relationship may be considerably different for single and multi-dowel connections. In the latter, the statically non-determinant load transfer results in different contributions of the individual dowels to the overall stiffness. 
Only a selected range of configurations and connection parameters were investigated herein. In order to build a solid foundation for a re-formulation of design formulae, further test series should be carried out. Variation parameters of interest include the dowel diameter, loading at an angle to the fiber direction of wood, the effects of defects such as knots, and the dowel number and dowel arrangement when considering multi-dowel connections. Besides experimental investigations, numerical simulations provide enhanced insight into the mechanical behavior of connections. In this context, the work provides a good reference basis and enables to validate simulation approaches across a large range of influence parameters. Own developments of suitable three-dimensional simulation tools are under way. The combination of numerical and experimental efforts will be the key to establishing improved design rules for connections in timber engineering.

\section{Acknowledgements}

The authors gratefully acknowledge the financial support of the Austrian Research Promotion Agency (FFG, project number 815234/12791) and the wood industry partnership Building with Wood within CEI-Bois for funding the research work within project MechWood. This work forms part of that project. The MechWood research partners are thanked for their cooperation and collaboration in this project.

Furthermore, the authors would like to thank the Institute of Wood Science and Technology, University of Natural Resources and Applied Life Sciences, Vienna, Austria, for the preparation of the specimens, the steel construction company Zeman \& Co GmbH, Vienna, Austria, for providing the steel plates, and the Research Center of Structural Concrete, Institute of Structural Engineering, Vienna University of Technology, Vienna, Austria, for providing testing equipment.

In addition, we would like to thank Dr. phil. Roland Reihsner (IMWS) for performing the tests and for his help during preparation of the experiments.

\section{Appendix A. Results of individual test series}

[1] K. Johansen, Theory of Timber Connections, in: International Association for Bridge and Structural Engineering (IABSE) Pub. 9, 1949, pp. 249-262. 
[2] Eurocode 5: Design of timber structures - Part 1-1: General - Common rules and rules for buildings (12 2010).

[3] N. Gattesco, I. Toffolo, Experimental study on multiple-bolt steel-totimber tension joints, Materials and Structures/Materiaux et Constructions 37(2) (2004) 129-138.

[4] J. Sjödin, E. Serrano, A numerical study of methods to predict the capacity of multiple steel-timber dowel joints, Holz als Roh - und Werkstoff 66 (2008) 447-454.

[5] A. Awaludin, T. Hirai, T. Hayashikawa, Y. Sasaki, Load-carrying capacity of steel-to-timber joints with a pretensioned bolt, Journal of Wood Science 54(5) (2008) 362-368.

[6] P. Cachim, J.-M. Franssen, Numerical modelling of timber connections under fire loading using a component model, Fire Safety Journal 44(6) (2009) 840-853.

[7] J. Sjödin, E. Serrano, An experimental study of the effects of moisture variations and gradients in the joint area in steel-timber dowel joints, Holzforschung 62(2) (2008) 243-247.

[8] D. R. Rammer, S. G. Winistorfer, Effect of moisture content on dowelbearing strength, Wood and Fiber Science 33 (1) (2001) 126-139.

[9] J. Schoenmakers, A. Jorissen, A. Leijten, Evaluation and modelling of perpendicular to grain embedment strength, Wood Science and Technology (2009) 1-17.

[10] J. Jensen, Splitting strength of beams loaded perpendicular to grain by dowel joints, Journal of Wood Science 51 (5) (2005) 480-485.

[11] A. Bouchair, A. Vergne, An application of the Tsai criterion as a plastic flow law for timber bolted joint modelling, Wood Science and Technology 30 (1) (1996) 3-19.

[12] N. Kharouf, G. McClure, I. Smith, Elasto-plastic modeling of wood bolted connections, Computers and Structures 81(8-11) (2003) 747-754. 
[13] L. Daudeville, L. Davenne, M. Yasumura, Prediction of the load carrying capacity of bolted timber joints, Wood Science and Technology 33(1) (1999) 15-29.

[14] M. Oudjene, M. Khelifa, Elasto-plastic constitutive law for wood behaviour under compressive loadings, Construction and Building Materials 23 (2009) 3359-3366.

[15] J. González Fueyo, M. Dominguez, J. Cabezas, M. Rubio, Design of connections with metal dowel-type fasteners in double shear, Materials and Structures/Materiaux et Constructions 42(3) (2009) 385-397.

[16] E. Resch, M. Kaliske, Three-dimensional numerical analyses of loadbearing behavior and failure of multiple double-shear dowel-type connections in timber engineering, Computers and Structures 88 (3-4) (2010) $165-177$.

[17] J. Sjödin, E. Serrano, B. Enquist, An experimental and numerical study of the effect of friction in single dowel joints, Holz als Roh - und Werkstoff 66(5) (2008) 363-372.

[18] Metallic materials - Tensile testing - Part 1: Method of test at room temperature (ISO 6892-1:2009) (12 2009).

[19] Timber structures; Joints made with mechanical fasteners; General principles for the determination of strength and deformation characteristics (ISO 6891 : 1983) (07 1991).

[20] L. A. Soltis, The Encyclopedia of Wood, Skyhorse Publishing, 2007, Ch. 7: Fastenings, pp. 7-1-7-28. 


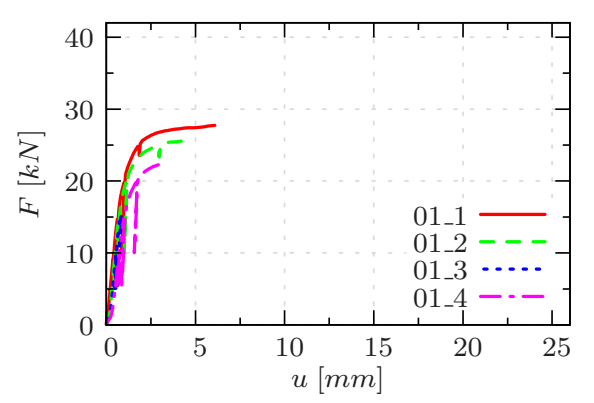

(a) Series 01

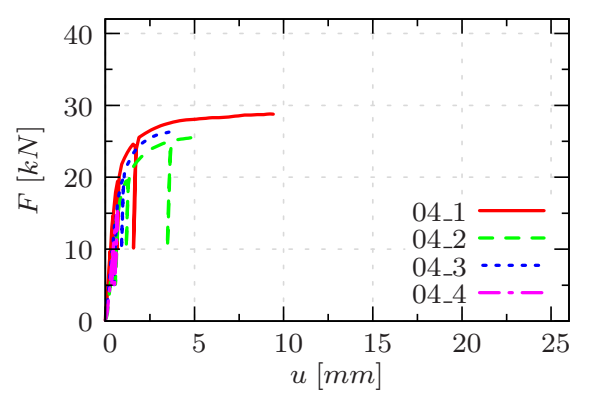

(c) Series 04

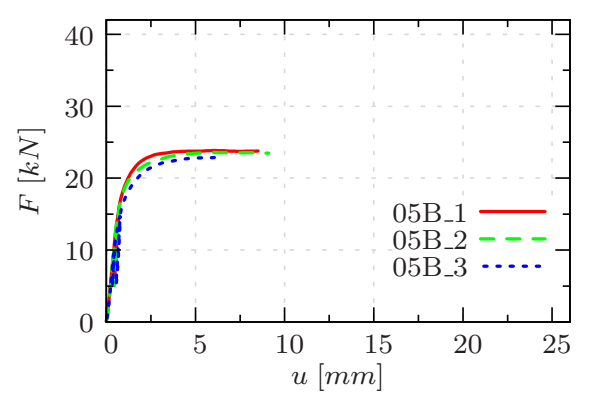

(e) Series 05B

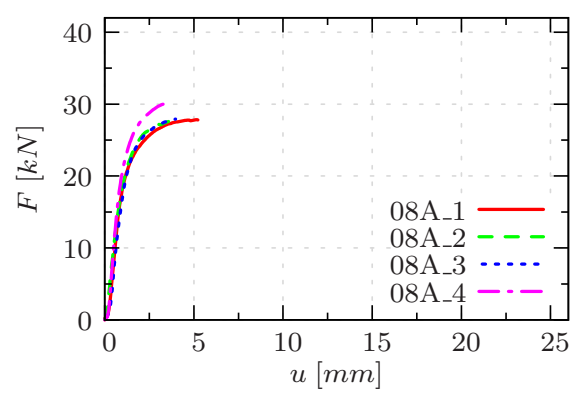

(g) Series 08A

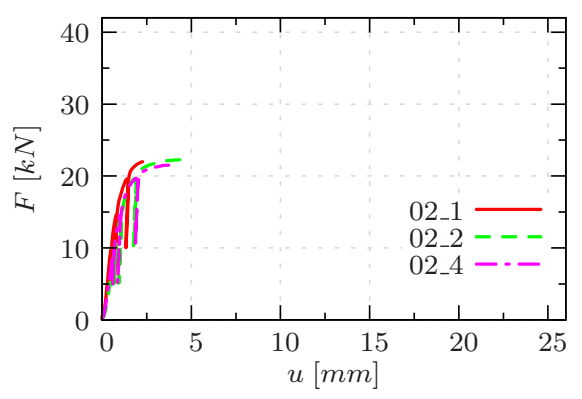

(b) Series 02

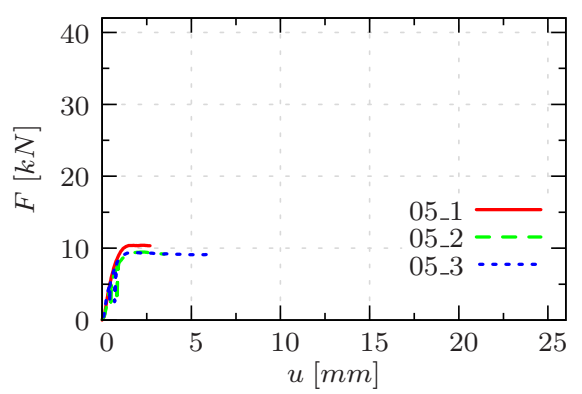

(d) Series 05

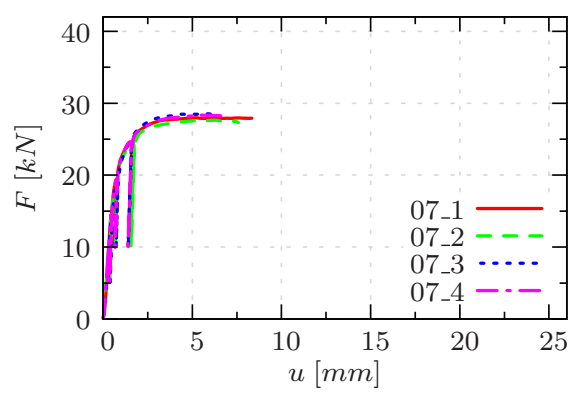

(f) Series 07

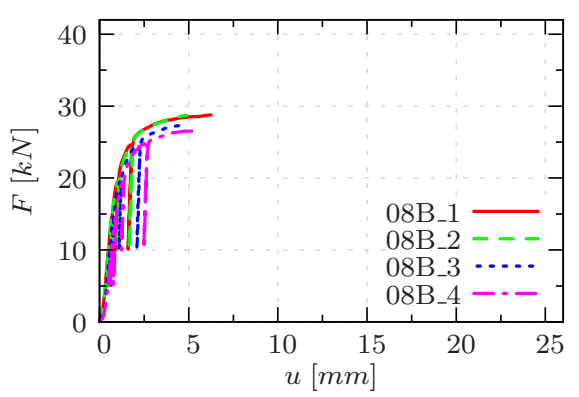

(h) Series 08B 


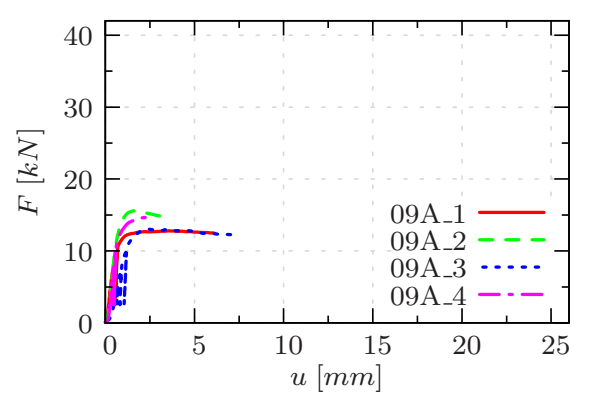

(i) Series 09A

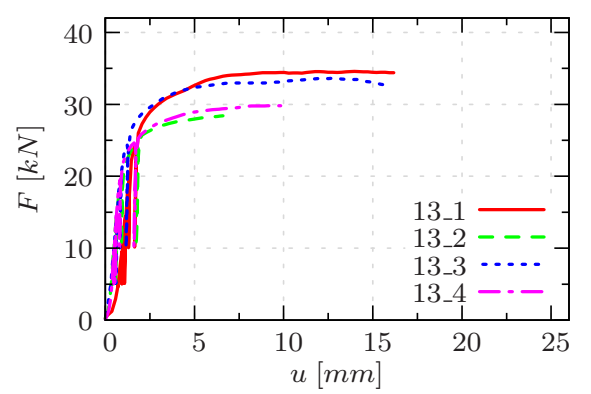

(k) Series 13

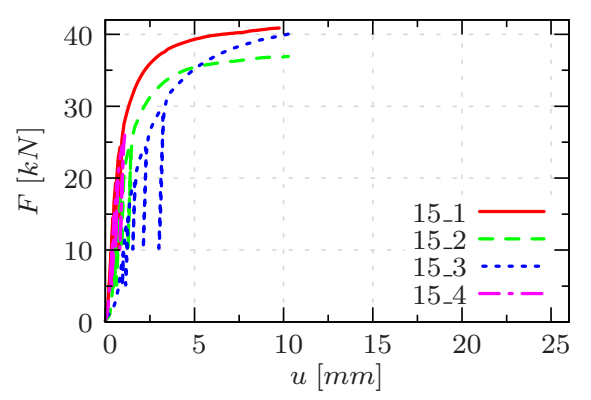

(m) Series 15

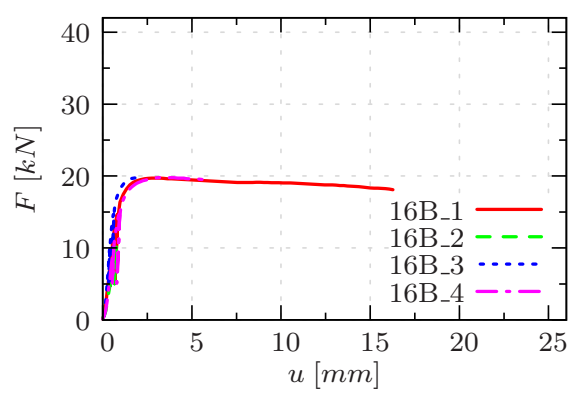

(o) Series 16B

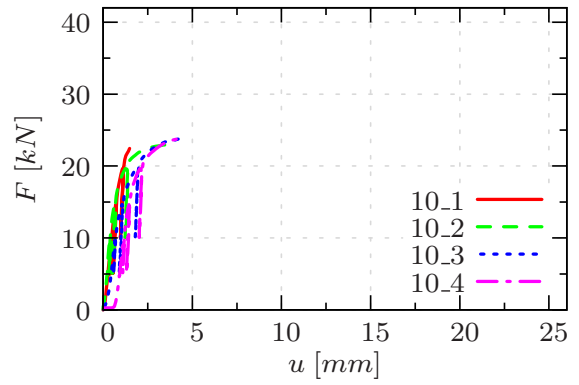

(j) Series 10

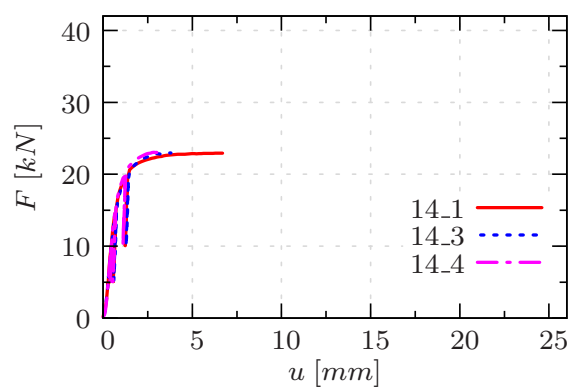

(l) Series 14

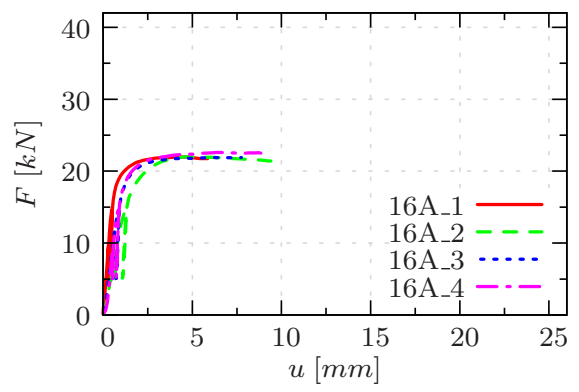

(n) Series 16A

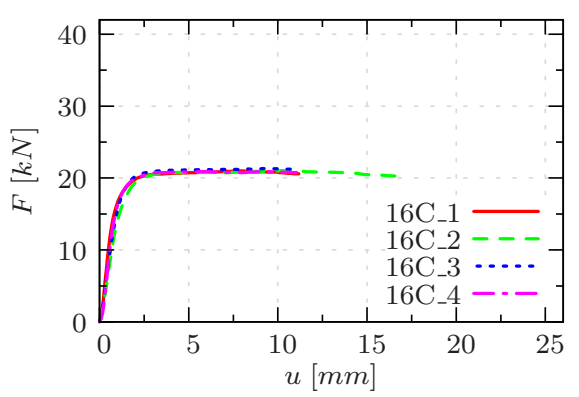

(p) Series 16C 


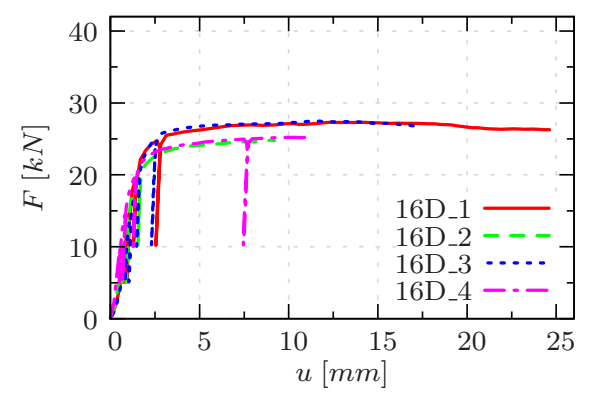

(q) Series $16 \mathrm{D}$

Figure A.15: Load-displacement curves for all specimens of all series 